\title{
Remote Laboratory: Application and usability
}

Luis C. M. Schlichting, Golberi de S. Ferreira, Daniel

D. de Bona, Flavio de Faveri, José A. Anderson

Electronic Academic Department

Federal Institute of Santa Catarina - Campus Florianópolis

Florianópolis, Brazil

schlicht@ifsc.edu.br ; golberi@ifsc.edu.br ;

dezan@ifsc.edu.br, flaviodf@gmail.com,

ja_anderson93@hotmail.com

\author{
Gustavo R. Alves \\ Department of Electrical Engineering \\ Polytechnic of Porto - School of Engineering \\ Porto, Portugal \\ gca@isep.ipp.pt
}

\begin{abstract}
The practice and the hands-on are essential for technical and professionals skills, even in controlled situations. Due to that, the use of laboratories during the learning process is fundamental, although it has been more difficult to support such kind of infrastructure locally, which brings the challenge to find alternatives. On the other hand, the Brazilian law establishes that higher education institutions can offer a complete curricula or a part of the curricula by using E-learning, what builds a scenario to use remote laboratories. This work presents the alternatives for the use of remote laboratories, showing that this idea can be spread and applied in different technical areas allowing students and professors to accomplish experiments in a safe and flexible environment trough the internet in real remote laboratories. This work also shows preliminary discussions of a first experiment with technical high school students using remote laboratories.
\end{abstract}

Keywords-Remote Laboratory, Remote Learning, Blended Learning, E-learning.

\section{INTRODUCTION}

In December 95 it was published in Brazil the law that conduces all the education processes in the country. This law establishes that higher education institutions can offer undergraduate courses using E-learning with $100 \%$ of the total curricula. In December 2004 it was published an ordinance allowing undergraduate courses to use up to $20 \%$ of the total curricula in E-learning to encourage the use of this methodology [4].

In the beginning, the E-learning was better received for private institutions in non technical courses. To increase the use in public institutions, in July 2008 the Open University of Brazil (UAB - Universidade Aberta do Brasil) was created to offer E-learning courses in public institutions [4]. This action from the Ministry of Education (MEC - Ministério da Educação) brought valuable results. However, they are still facing technical difficulties with the courses that need laboratories, so they cannot adapt to this new reality of learning

This project has been funded with support from the European Commission. This publication reflects the views only of the authors, and the Commission cannot be held responsible for any use which may be made of the information contained therein". as fast as desired. Moreover, the courses that uses laboratories and practical experiments have to find new tools to allow students to have the same qualitative results as those who uses local laboratories.

This situation brings a discussion about the significance of the physical experiments for the students from technical areas. It is well-known that the practical/theoretical learning is fundamental for a student of a technological course due to the occurrence of the many phenomena in reality that may not be observed in theoretical models.

For those professionals who have passed through all the steps of a scientific carrier, those practical and theoretical differences are known. However, a student needs to verify by himself/herself dialectically going from practical to theoretical and vice-versa, improving the knowledge of the phenomena.

For most of these courses, this issues are solved by the use of dialogue lectures and practical experiments in laboratory. However, when the propose changes for E-Learning method, which uses the internet, the question come out: "How to guarantee the same quality of learning as the classroom method?". This kind of question has brought practical/theoretical barriers, and also brought barriers created by the professors that looks E-learning initiative unworkable.

The most important concern is to exchange the physical laboratories to a model that offers the same quality of learning.

Computer simulations have been used for a long time, however, the process to obtain the results often uses theoretical models that do not consider all phenomena of the real world. Due to that, when simulation takes place, the results could be far from the reality. In terms of learning, that situation could create a false understanding, taking from the student the possibility to find a problem and fix it trough the relation between practice and theory [10].

Moreover, another problem about the use of computer simulation is having different result between theory and practice, mainly when the circuit (in electrical/electronic area) works at high frequencies, because the computer frequency calculation could be not enough to guarantee a good signal 
representation, adding an error to the circuit. Despite of that, the biggest advantage of the computer simulations is the learning from theoretical models developed by reliable references [7], [8].

The ideal method should be the one that combine the advantage of the computers and internet, like computer simulation, and the practical experiments from physical laboratories where the student could build the circuitry, doing connections and measurements with instruments. This kind of method already exists and have been developed around the world through the years as Remote Laboratories. A Remote Laboratory is a physical module that combines a server to communicate with the clients through the internet on a web service and dedicated circuit boards for the experiments, where the electronic components and instruments are connected. This method allows the laboratory to be built in a specific place to be accessed all around the world to accomplish real experiments [12].

The remote laboratories give to the students the same experience as they have in local laboratories because the circuits are built with real components on the boards and the results are shown from the real measurements taken from real instruments as oscilloscopes, signal generators and so on. All that experience is part of the students learning process and gives them an important emotional stimulus [7],[8].

Another important characteristic of remote laboratories is that the experiments could be done anytime and from anywhere, without the presence of the professor or a technical staff. This characteristic provides more flexibility for professors that can use the classroom period for dialogue lectures and theoretical explanations instead of use the whole class time to organize and accomplish the experiments. Moreover, some remote laboratories have virtual chat rooms for discussion and the presence of a professor tutor can be provided to solve more difficult issues [7],[8],[9],[10].

Not only the practical experiment is the important thing to the student, but also the use of the instruments for measurements. In most of the technological courses, it is a fundamental skill having the ability to use the instruments like oscilloscopes, signal generator, multimeter, etc. However, during the classes it is difficult to find time to explain for each student individually how to use in detail every instruments due to the amount of theoretical contents. By using the remote laboratories, it is possible to create a tutorial, aiming to teach the student how to handle the instruments in a safe environment, either for the students life safety and for the equipment damage security [7].

\section{APPLICATION}

All around the world, remote laboratories have shown the potential to give support for different subject's curricula as engineering, biology and physic, for instance. This support confirms the efficiency of an environment that emulates the reality, excluding a lot of problems related to the operation of real laboratories. Obviously, this observation does not aim to debunk the practice in the local laboratories, although the understanding of the importance of new learning tools should be considered to increase the offer of courses with lower costs of installation, operation and maintenance.

Some examples of remote laboratories that have been used along the years are: the Virtual Instrument Systems in Reality (VISIR), the Aquarium, the Shake Table 2DOF, the Turbulent to Laminar Flow, the Truss Testing and the Virtual Machines. All of that platforms are used in different proposes. The first one is a real laboratory that are connected to the internet where the student can build electronic experiments with preset components and remotely verify the signals. The second one allows dairy verification of an underwater life in an aquarium where the user can feed the fishes and turn the lights on, watching all movements on a video streaming, also remotely [1],[2],[3],[5],[6],[13].

The Shake Table 2DOF is an experiment where a solid base can move with the amplitude and frequency remotely controlled. It allows the students to understand and test different shapes and structures that can have a better response for earthquakes and natural associated phenomena. The Truss Testing allows the students verify the response for mechanical tension and mechanical compression on truss structures. Both of them are used for students from civil engineering, physics or mechanical fields and could be applied for tests in bridge structures, for instance [1], [2].

The Turbulent to Laminar Flow allow to check the oil flow through a pipe from a turbulent region to a laminar region where the concepts of mechanical engineering and chemistry can be remotely verified. These experiments use a kind of hardware developed for a specific propose and the response can be physically, but remotely measurable.

The Virtual Machines Laboratory emulates a Linux based virtual machine to allow the students to do different software experiments. During the experiment, the student is free to use all resources and after finish it, the system auto recover. This last examples shows that even areas that do not use a specific hardware, for instance computing and related areas, can also be comprised by remote laboratories [3], [6].

Apart from all of that laboratories that are already installed, a lot of effort has been doing to increase the range of the possibilities for remote laboratories. Another applications have been tested using micro controllers, robotics, FPGA and sequential logic. However, there is a plenty of work to do to guarantee that the technology applied in remote laboratories comply with the quality of the learning process. It is possible to verify by the examples that there is a wide range of feasible applications in different areas which could be implemented shortly.

Those mentioned laboratories are installed mainly in countries like Spain and Australia, however other countries like Portugal, Sweden, Austria, India and Brazil also have some experiments and their knowledge about remote laboratories have been improved. The aim is that the number of partners and experiments grows up to allow more students to have access to this technology to improve the skills and the knowledge by using remote laboratories. Also it is important to have the cooperation from different countries to incorporate the expertise of each one to reach more knowledge areas. 


\section{A. The use of remote laboratories with a group of volunteers students in IFSC}

In 2014 and 2015, a group of professors from Federal Institute of Education, Science and Technology of Santa Catarina - Brazil (IFSC), accomplished two experiments with a group of fifteen students from the subject "Operational Amplifiers", when it was provided a tutorial to access the VISIR platform and the schematic circuit. At this point, it was not informed to the students that the main propose of the experiment was to know the applicability on electronic learning and if the students will adapt themselves in a natural way to the use of this new platform. This decision was applied to guarantee that the students will not be forced to think on how this works when they execute the experiment, forcing them to act as natural as possible [11].

The results showed that the activity was well executed and after that, professors and students discussed the pros and cons of the tool. Some of them said that it is quite similar as the use of local laboratories due to the way that the components and instruments are used and positioned, and how the features are accessed. On the other hand, some of hem said that they imagine the real experiment as a simulation because the commands and the results are shown in a computer screen. However, there was one point in common which is that the method do not substitute the practice, but is an excellent tool to improve their knowledge.

\section{B. Adding remote experiments using VISIR on the electronic subjects}

Considering the results from the experiment with the students from he subject "Operational Amplifiers" and their acceptance about the new methodology, the professors decided to define another subjects in the courses offered by the Electronic Academic Department (DAELN - Departamento Acadêmico de Eletrônica) of IFSC. It was applied a questionnaire with nine professors from DAELN that were willing to collaborate with the project. Those professors worked in 2014/2 and 2015/1 with different subjects for Electronic Technical Courses (secondary level), Electronic Technological and Electronic Engineering Courses (undergraduate level), and Post Graduation in Development of Electronic Products. The questions that was applied to the survey was:

1. How many experiments did you accomplish on the subject?

2. From those accomplished, or further than that, how many experiments could be done with remote laboratories?

So that teachers could answer those two questions, it was offered a training course to explain VISIR system and also the experiment conducted with students. It was also performed the implementation of a remote experiment to understand how the system works.

The research was made analyzing two semesters, to confirm remote laboratories application in a continuous way, because there is a difference in the offered disciplines between the first and second semesters.
Figures 1 to 8 show the results obtained with the answers of the teachers. These answers were compiled and grouped not by discipline but by areas. The defined areas are:

- Circuits Analysis

- Analog Electronics

- Digital Electronics

- Electronic Processing of Energy

Analysing figures 1 until 4, one can realize that for the subjects "Circuit Analysis" and "Analog Electronics" the number of experiments can be higher by using remote laboratories than it is today due to the flexibility of the use of remote experiments. That's why the "Applicable Experiments" could be higher than "Accomplished Experiments". This can be explained by the amount of expended time on the preparation of the local laboratory for practical experiments, meanwhile the remote laboratories are already prepared to interact and respond to the experiments as soon as the user is connected. This extra time to prepare the local laboratory could be used to explain more details of the experiments and also to provide discussions between the students about the results, beside of the increase of the number of experiments.

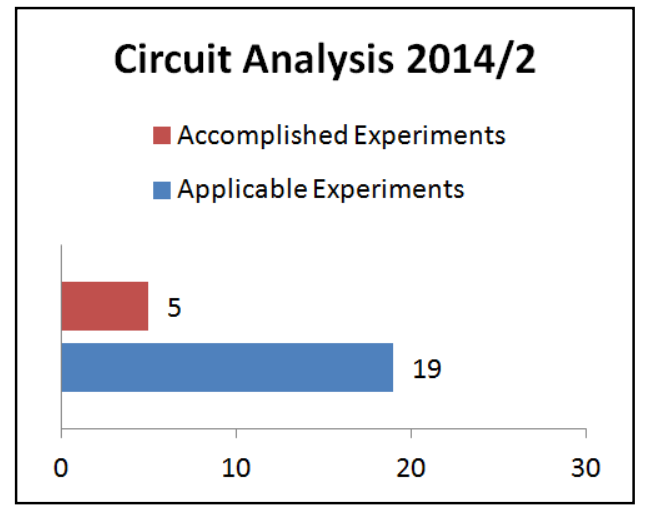

Fig. 1. Circuit analysis 2014/2

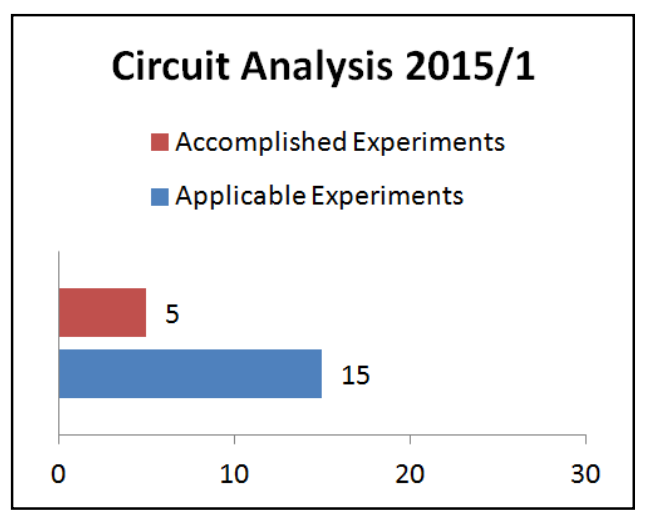

Fig. 2. Circuit analysis 2015/1 


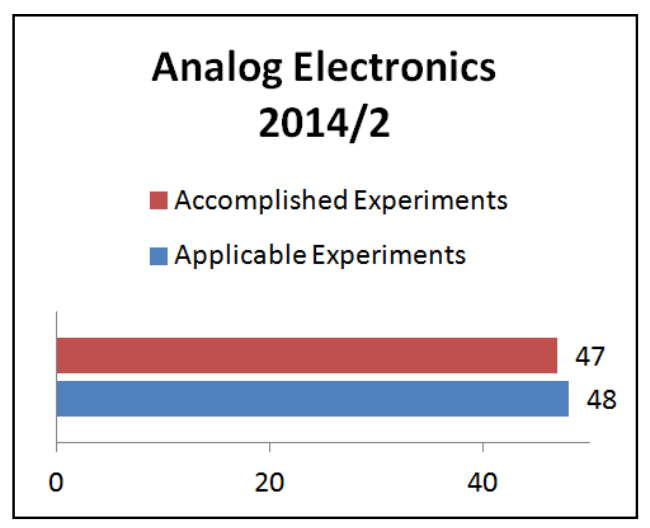

Fig. 3. Analog Electronics 2014/2

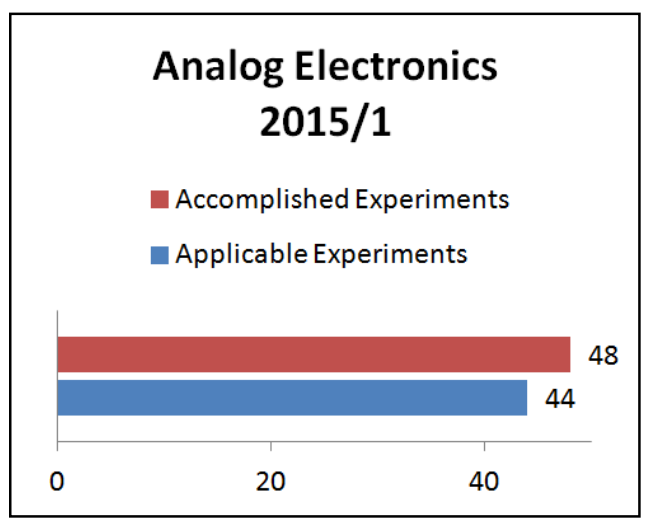

Fig. 4. Analog Electronics 2015/1

As can be observed in Figures 5 and 6, in the digital electronics area the number of experiments in which we can use the remote laboratories is smaller than those which were performed. The main cause for such characteristic is that VISIR is more appropriate for combinational logic than for sequential logic

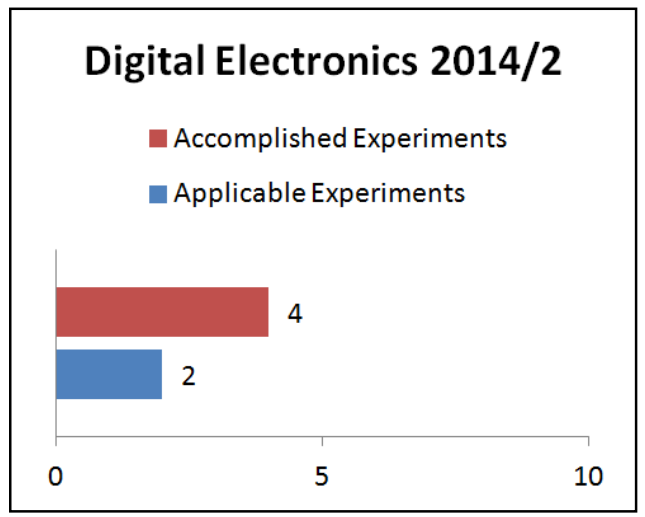

Fig. 5. Digital Electronics 2014/2

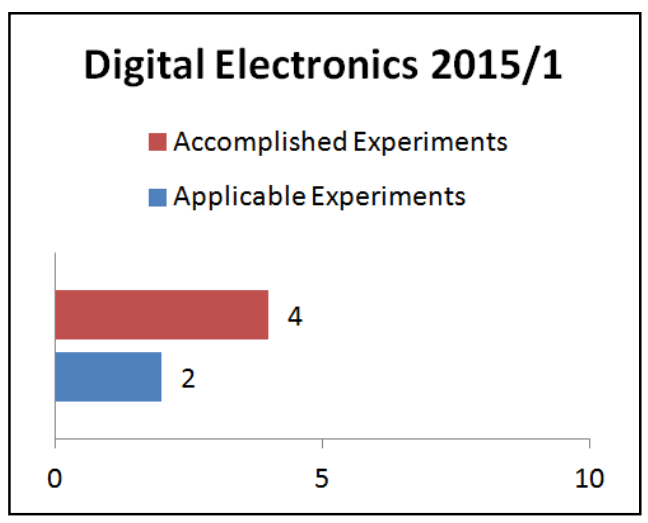

Fig. 6. Digital Electronics 2015/1

In the Figures 7 and 8 where the data of the discipline Electronic Processing of Energy are presented, we can see a big difference in the amount of experiments from one semester to another. However, the number of possible experiments remained, in percentage terms. This variation is because in the first semester $(2015 / 1)$ it was included more subjects in this area.

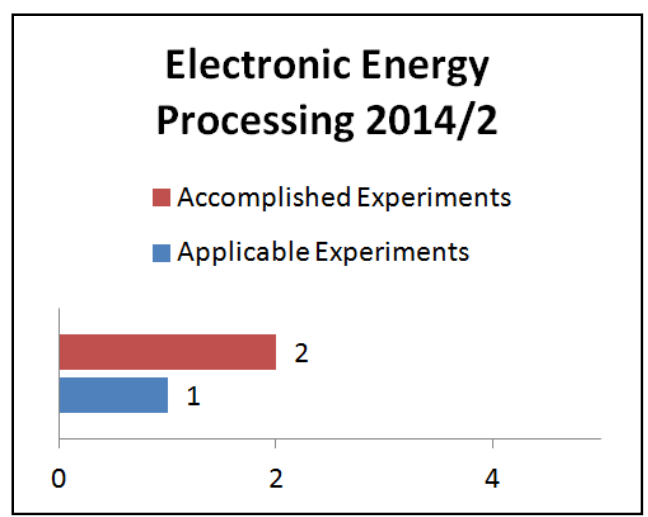

Fig. 7. Electronic Energy Processing 2014/2

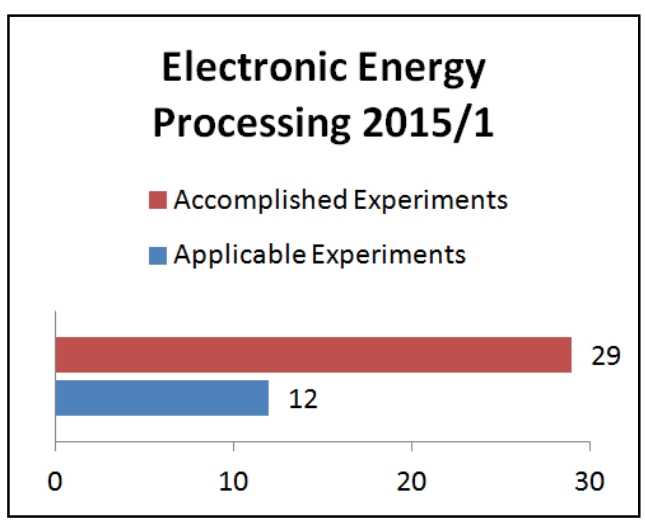

Fig. 8. Electronic energy Processing 2015/1

Figures 9 and 10 show the total numbers for 2014/2 and $2015 / 1$, and it is important to explain the difference between the graphics of Total Experiments in 2014/2 and 2015/1. While in $2014 / 2$ there is $120 \%$ possibility of the use of VISIR in the experiments, therefore, increasing the number of experiments that were accomplished without VISIR, in $2015 / 1$ only $88 \%$ 
were defined as possible to be executed with VISIR. This could be explained because of the inter exchange of the subjects between professor at DAELN and the difference of the offered subjects in each semester.

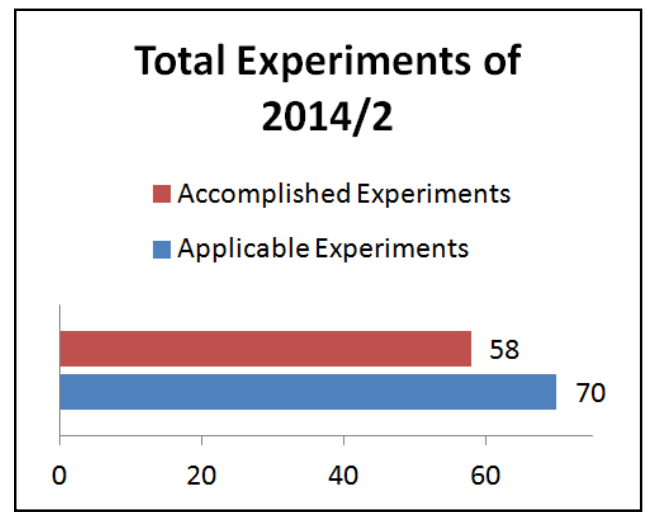

Fig. 9. Total experiments 2014/2

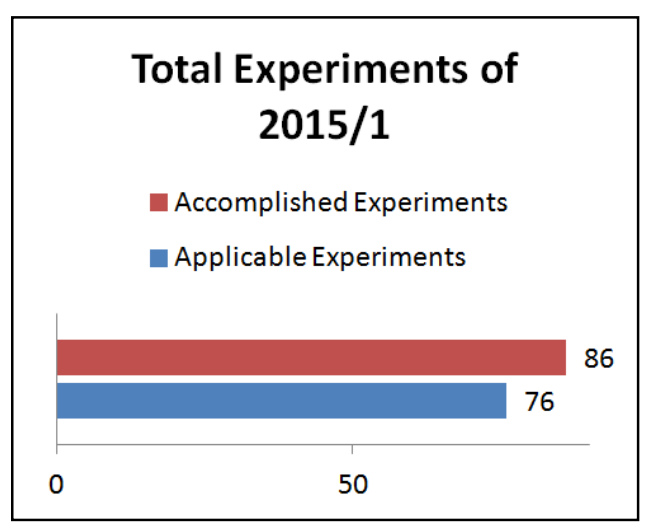

Fig. 10. Total experiments $2015 / 1$

\section{FINAL DISCUSSION}

There are different areas that can be reached by using remote laboratories as shown before as: underwater life behavior, mechanical and physics structures, and so on [1],[2],[3],[5],[6],[13]. However, this paper aims to emphasize the applications for electric-electronic area on the curricula of the technical, undergraduate and post graduated courses. Although it is also possible to think about short time courses.

Considering the ratio cost $\mathrm{x}$ benefit, the time, the opportunities, the increase of the offer, we can imply that the use of remote laboratories is more than an option, it is an urgent necessity. Therefore, all the efforts expended to this way will be recompensed later. Local laboratories will always be necessary, but remote labs are a clever and profitable solution.

Considering the results from the survey with the staff of DAELN, it is possible to verify the interest of the professors about the use of remote laboratories due to the significance of the answer for the second question: " 2 . From those accomplished, or further than that, how many experiments could be done with remote laboratories?".

Whereas most all of the subjects surveyed presented the possibility to implement remote experiments, the Programmable Logical Device (PLD) subject was the unique that was not able to perform any experiment on remote laboratory. As the VISIR do not support PLD experiments it is not possible to use this tool at this moment. However, there are other tools for this specific application, which shows that it is possible to implement remote laboratories on that subject.

This paper presents an analysis that shows the potential and, primarily, the feasibility of applying the remote laboratories technology, more specifically, in the courses of the Electronics Academic Department of IFSC. This indicates how important and feasible is the IFSC participation in the VISIR project.

\section{ACKNOWLEDGMENT}

The authors would like to acknowledge the support of the Polytechnic of Porto - School of Engineering for allowing the use of the VISIR as a remote laboratory for experiments with IFSC students. A VISIR system is to be installed at the Federal Institute of Santa Catarina (IFSC), during 2016, with the support of the Erasmus + programme, under grant 561735-EPP1-2015-1-PT-EPPKA2-CBHE-JP .

\section{REFERENCES}

[1] Australia. The University of Sydney. Shake Table 2DOF. Avaiable at: $<$ http://www.labshare.edu.au/>. Accessed on April 2015.

[2] Australia. The University of Sydney. Truss Testing. Avaiable at: $<$ http://www.labshare.edu.au/>. Accessed on April 2015.

[3] Australia. The University of Sydney. Turbulent to Laminar Flow. Avaiable at: <http://www.labshare.edu.au/>. Accessed on April 2015 .

[4] Censo da educação superior: 2011 - resumo técnico. - Brasília : Instituto Nacional de Estudos e Pesquisas Educacionais Anísio Teixeira, 2013

[5] Spain. University of Deusto. Aquarium Lab. Avaiable: $<$ http://weblabdeusto.readthedocs.org/en/latest/sample labs.html\#aquari um>. Accessed on April 2015.

[6] Spain. University of Deusto. Virtual Machine Lab. Avaiable at: $<$ http://weblabdeusto.readthedocs.org/en/latest/sample_labs.html\#virtual -machine-lab>. Accessed on April 2015.

[7] Gustavsson, I. et al. On Objectives of Instrucional Laboratories, Individual Assessment, and Use of Collaborative Remote Laboratories. IEEE Transactions on Learning Technologies, v.2, nº 4 , p.263-273, oct.dez. 2009.

[8] Gustavsson, I. Student's Guide to the VISIR Remote Laboratory for Electrical Experiments. 2009. Avaiable at: $<$ http://openlabs.bth.se/static/Student_manual5.pdf $>$. Accessed on February 2015.

[9] MA, J.; Nickerson, J. V. Hands-On, Simulated, and Remote Laboratories: A Comparative Literature Review. ACM Computing Surveys, v.38, no 3 , p.1-17, set. 2006.

[10] Nedic, Zorica; Machota, Jan; Nafalskt, Andrew. Remote Laboratories versus Virtual and Real Laboratories. Em: ASEE/IEEE Frontiers in Education Conference, 33., 2003, Boulder. Paper. Boulder: IEEE, 2003. p. $1-6$.

[11] Schlichting, Luis C. M.; et al. Enriched scenarios for teaching and learning electronics. Technologies Applied to Electronics Teaching (TAEE), 2014, Bilbao. Paper. Bilbao: IEEE, 2014.

[12] Tawfik, M. et al. Virtual Instrument Systems in Reality (VISIR) for Remote Wiring and Measurement of Electronic Circuits on Breadboard. IEEE Transactions on Learning Technologies, v.6, $\mathrm{n}^{\mathrm{o}}$ 1, p.60-72, 2013.

"This project has been funded with support from the European Commission. This publication reflects the views only of the authors, and the Commission cannot be held responsible for any use which may be made of the information contained therein". 
[13] Tawfik, M. VISIR Installation \& Start-Up Guide. Electric, Electronic and Control Department Spanish University for Distance Education UNED, mar. 2001, 43p 
